CZU 349.23:364.3

DOI: https://doi.org/10.52388/2345-1971.2021.1.13

\title{
ANALYSIS OF THE LAW OF THE REPUBLIC OF MOLDOVA ON THE GRANTING OF COMPANSATION IN THE EVENT OF THE DEATH OF ONE OF THE SPOUSES
}

\author{
Tudor CAPSA \\ Doctor of Law, Associate Professor, Labor Relations Research Center, \\ Chisinau, Republic of Moldova \\ e-mail: tudor.capsa@gmail.com \\ https://orcid.org/0000-0001-6333-1016
}

The article analyzes in detail and comments article by article the main legal aspects of the Law of the Republic of Moldova on the provision of benefits in the event of the death of one of the spouses No. 156/2019 through the prism of the norms and prescriptions of the national legislation on social insurance and social security, as well as their practical and correct application, with the formulation in the process of presenting the material of substantiated conclusions and recommendations on the multifaceted and topical topic under consideration.

At the same time, the comments contained in this article are intended to assist faculty, doctoral students, undergraduates and students of law schools / faculties and scientific researchers of organizations / centers in the field of science and innovation in the systemic assimilation of social insurance and social security norms., regulating the procedure for registration and payment of benefits due to the death of one of the spouses.

In addition, these comments are aimed at correct / accurate understanding and application of the provisions of the current laws and regulations on social insurance and social security by employees of social insurance and social assistance / protection authorities at all levels, lawyers, inspectors of human resources services, representatives of social partners and non-governmental organizations. , entrepreneurs, judges, prosecutors, lawyers, mediators, trade unionists and activists, interested employees and government officials.

Keywords: legislation, social insurance, social security, deceased spouse, pension, benefit.

\section{ANALIZA LEGII REPUBLICII MOLDOVA CU PRIVIRE LAACORDAREA INDEMNIZAT,IEI ÎN CAZUL DECESULUI UNUIA DINTRE SOȚI}

Prezentul articol analizează în detaliu și oferă comentarii, articol cu articol, referitoare la principalele aspecte juridice ale Legii Republicii Moldova nr. 156/2019 Cu privire la acordarea indemnizației in cazul decesului unuia dintre soți prin prisma normelor și prescripțiilor legislației naționale privind asigurările sociale și securitatea socială, precum și aplicarea lor practică și corectă, cu formularea în procesul de expunere a materialului a concluziilor și recomandărilor fundamentate pe marginea temei multifacetice și actuale cercetate.

Totodată, comentariile cuprinse în acest articol sunt destinate să acorde asistență corpului profesoral-didactic, doctoranzilor, masteranzilor, studenților instituțiilor superioare de învățământ/facultăților de drept și cercetătorilor științifici ai organizațiilor/centrelor din domeniul științei și inovațiilor în asimilarea sistemică a normelor asigurărilor sociale și de asistență socială, ce reglementează modul de solicitare și plată a indemnizației în urma decesului unuia dintre soți.

În plus, aceste comentarii sunt orientate spre înțelegerea și aplicarea corectă/exactă a prevederilor actelor legislative și normative în vigoare privind asigurările sociale și securitatea socială de către angajații organelor de asigurări sociale și organelor de asistență/protecție socială la toate nivelurile, juriști, inspectorii serviciilor resurse umane, reprezentanții partenerilor sociali și ai organizațiilor ne- 
guvernamentale, antreprenori, judecători, procurori, avocați, mediatori, lucrători și activiști sindicali, salariați și funcționari publici interesați.

Cuvinte-cheie: legislație, asigurare socială, asistență socială, soț decedat, pensie, indemnizație.

\section{ANALYSE DE LA LOI DE LA RÉPUBLIQUE DE MOLDOVA SUR L'OCTROI DES PRESTATIONS EN CAS DE DÉCÈS DE L'UN DES ÉPOUX}

L'article analyse en détail et commente article par article les principaux aspects juridiques de la loi de la République de Moldova sur l'octroi des prestations en cas de décès de l'un des époux ${ }^{\circ}$ 156/2019 à travers le prisme des normes et les réglementations de la législation nationale sur les assurances sociales et la sécurité sociale, ainsi que leur application pratique et correcte, avec la formulation en cours de présentation du matériel de conclusions et de recommandations étayées sur le sujet à multiples facettes et d'actualité à l'étude.

Dans le même temps, les commentaires contenus dans cet article visent à aider les professeurs, les doctorants, les étudiants de premier cycle et les étudiants des facultés / facultés de droit et les chercheurs scientifiques des organisations / centres dans le domaine des sciences et de l'innovation dans l'assimilation systémique des assurances sociales et normes de sécurité sociale., réglementant la procédure d'enregistrement et de paiement des prestations en cas de décès de l'un des époux.

En outre, ces commentaires visent à la compréhension et à l'application correctes / précises des dispositions des lois et règlements en vigueur sur les assurances sociales et la sécurité sociale par les employés des assurances sociales et des autorités d'assistance / protection sociale à tous les niveaux, avocats, inspecteurs services de ressources, représentants des partenaires sociaux et des organisations non gouvernementales., entrepreneurs, juges, procureurs, avocats, médiateurs, syndicalistes et militants, employés intéressés et fonctionnaires.

Mots-clés: législation, assurance sociale, sécurité sociale, conjoint décédé, pension, prestation.

\section{АНАЛИЗ ЗАКОНА РЕСПУБЛИКИ МОЛДОВА О ПРЕДОСТАВЛЕНИИ ПОСОБИЯ В СЛУЧАЕ СМЕРТИ ОДНОГО ИЗ СУПРУГОВ}

В статье детально анализируются и комментируются постатейно основные правовые аспекты Закона Республики Молдова № 156/2019 О предоставлении пособия в случае смерти одного из супругов сквозь призму норм и предписаний национального законодательства о социальном страховании и сочиальном обеспечении, а также их практического и правильного применения, с формулированием в прочессе изложения материала обоснованных выводов и рекомендачий по рассматриваемой многогранной и актуальной теме.

Наряду с этим, комментарии, содержащиеся в данной статье, призваны оказать помощь профессорско-преподавательскому составу, докторантам, магистрантам и студентам юридических высших учебных заведений/факультетов и научным исследователям организаций/центров в области науки и инноваций в системном усвоении норм социального страхования и соииального обеспечения, регламентирующих порядок оформления и выплаты пособия по причине смерти одного из супругов.

Помимо этого, данные комментарии нацелены на правильное/точное понимание и применение положений действующих законодательных и нормативных актов о сочиальном страховании и соииальном обеспечении работниками органов сочиального страхования и органов сочиальной помощии/защиты всех уровней, юристами, инспекторами кадровых служб, представителями социиальных партнеров и неправительственных организаций, предпринимателями, судьями, прокурорами, адвокатами, медиаторами, профсоюзными работниками и активистами, заинтересованными наемными работниками и государственными служащими.

Ключевые слова: законодательство, сочиальное страхование, соииальное обеспечение, умерший супруг, пенсия, пособие.

\section{Введение}

Принятый молдавским Парламентом органический Закон № 156/2019 о предо- ставлении пособия в случае смерти одного из супругов [1] (далее - Закон № 156/2019) призван гарантировать Республикой Мол- 
дова (РМ) на определенный срок пережившему супругу права на ежемесячное пособие в размере пенсии по возрасту (ПВ), которую получал умерший супруг, в зависимости от продолжительности его получения.

Следует отметить, что государственная система социального страхования (ГССС) организована и действует на основании принципов, установленных в ст. 3 Закона № 489/1999 о государственной системе социального страхования [2], одним из которых является принцип участия, согласно которому реализация права на социальное страхование в нашей стране зависит от уплаты взносов социального страхования.

Помимо этого, в ГССС пособия застрахованным лицам предоставляются в деньгах в зависимости от уплаты взносов социального страхования. Таким образом, пенсия - это денежная сумма, которая выплачивается застрахованному лицу, имеющему на нее право на основании обязательной уплаты взносов государственного социального страхования, из отработанного лицом периода. Соответственно, государство обязано платить пенсию в пассивный период жизни, размер которой определяется по принципу его участия.

В этом контексте, комментируемый ниже Закон № 156/2019 исходит из принципа участия, стоящего в основе организации и функционирования ГССС. Он преследует цель обеспечения дополнительными финансовыми ресурсами пережившего супруга, путем компенсирования потерянного дохода вследствие смерти супруга, а также для укрепления доверия плательщиков к отечественной пенсионной системе.

Рассмотрим настоящий органический закон по-статейно.

Статья 1. Предоставление права на пособие в случае смерти одного из супругов

(1) В случае смерти одного из супругов, который получал пенсию по возрасту менее пяти лет после установления права на пенсию в соответствии с Законом о государственной пенсионной системе № 156/1998, пережившему супругу предоставляется ежемесячное пособие.

(2) Размер пособия устанавливается в размере пенсии по возрасту, выплачиваемой на день смерти получателя пенсии, но не может превышать в сумме пяти среднемесячных заработных плат, прогнозируемых по экономике на год, в котором наступила смерть этого лица.

(3) Пособие выплачивается ежемесячно в течение периода, рассчитываемого в соответствии с формулой: $\mathrm{T}=5-\mathrm{p}$, где:

T - период, в течение которого переживший супруг вправе получать пособие;

$\mathrm{p}$ - период, за который умерший супруг получил пенсию по возрасту.

(4) Пособие выплачивается в случае, если на день наступления смерти получателя пенсии переживший супруг состоял с ним в браке не менее 15 лет. Пособие предоставляется независимо от того, является ли переживший супруг получателем пенсии в государственной пенсионной системе, если пенсия, выплачиваемая пережившему супругу, или реализованный им в месяц смерти супруга застрахованный месячный доход не превышает в 1,5 раза прожиточный минимум для пенсионеров согласно данным, имеющимся у Национального бюро статистики на момент запроса пособия.

[Cm. 1 ч. (4) изменена 3П $37 \mathrm{om}$ 28.02.20, МО 84/14.03.20 cm. 86; в силе с 14.03.20]

(5) Право на получение пособия может быть востребовано пережившим супругом в течение трех лет со дня наступления смерти супруга.

1. Из содержания правовой нормы ч. (1) комментируемой ст.1 Закона № 156/2019 следует, что в случае смерти одного из супругов (мужа или жены), который получал 
ПВ (к данной пенсии не относятся другие виды пенсий, например, пенсия по ограничению возможностей; пенсия по случаю потери кормильца; специальная пенсия; досрочная пенсия по возрасту и др.) менее пяти лет (к примеру, получивший ПВ в течение 4 лет и 10 месяцев) после установления права на такую пенсию в соответствии с Законом о государственной пенсионной системе № 156/1998 [3] (далее - Закон о ГПС), пережившему супругу предоставляется ежемесячное пособие в связи со смертью своего супруга (ЕПСС).

Установление права на ПВ, о котором говорится в ч. (1) ст.1 Закона № 156/2019, производится в соответствии с основными требованиями ст. 14-17, 30-32 и 41 Закона о ГПС. В частности, исходя из требований ст. 14,15 и 41 Закона о ГПС право на ПВ возникает при выполнении условий о пенсионном возрасте и страховом стаже, предусмотренных настоящим законом. ПВ может назначаться по достижении стандартного пенсионного возраста, предусмотренного ст. 41 Закона о ГПС (потолок которого для мужчин достигнут 01.07.2019 г. и составляет 63 года, а для женщин с 01.07.2021 г. по 31.12.2021 г. - 59 лет и 6 месяцев), при условии наличия минимального страхового стажа 15 лет. Застрахованное лицо, которое по достижении стандартного пенсионного возраста не имеет упомянутого минимального страхового стажа (15 лет), вправе претендовать на получение социального пособия согласно Закону о государственных социальных пособиях некоторым категориям граждан № 499/1999 [4]. В случае если застрахованное лицо по достижении стандартного пенсионного возраста не реализовало своевременно право на ПВ (по тем или иным причинам), при последующем назначении ПВ учитывается страховой стаж, приобретенный до дня обращения (точнее, до даты регистрации письменного заявления о назначении ПВ).
Далее, правовыми требованиями ст. 3032 Закона о ГПС (о котором упомянуто в ч.(1) ст.1 Закона № 156/2019) предусмотрено, что пенсия (включая ПВ) назначается и выплачивается органом социального страхования (точнее, территориальной кассой социального страхования - ТКСС), который имеет право осуществлять контроль достоверности документов, подтверждающих трудовой стаж и застрахованный доход, выданных правомочными органами. ПВ назначается по заявлению лица, имеющего на нее право, его опекуна (попечителя). Заявление о назначении ПВ и необходимые документы представляются в ТКСС по месту постоянного жительства застрахованного лица, где в обязательном порядке регистрируются. Решение о назначении ПВ или об отказе в ее назначении выносится ТКСС и подписывается руководителем этого органа в 30-дневный срок со дня подачи заявления со всеми необходимыми документами. Решение об отказе в назначении ПВ с указанием причин отказа направляется заявителю в пятидневный срок со дня его вынесения. ПВ назначаются пожизненно. ПВ назначается со дня возникновения права на пенсию в соответствии с Законом о ГПС, если заявление и все необходимые документы были представлены не позднее 30 дней после этой даты. Если 30-дневный срок подачи заявления истек, ПВ назначается со дня представления последнего необходимого документа.

Следует также учесть, что поскольку норма ч.(1) ст.1 Закона № 156/2019 связывает выплату ЕПСС с получением умершим супругом ПВ в соответствии с Законом о ГПС, то при таких обстоятельствах, положения комментируемого закона не распространяются в случае смерти супруга, получавшего тот или иной вид пенсии на основании Закона о пенсионном обеспечении военнослужащих и лиц начальствующего и рядового состава органов внутренних дел и 
Генерального инспектората карабинеров № $1544 / 1993$ [5].

2. Предписаниями ч.(2) комментируемой ст.1 Закона № 156/2019 определено, что размер ЕПСС устанавливается в размере ПВ, выплачиваемой на день смерти получателя пенсии, но не может превышать в сумме пяти среднемесячных заработных плат, прогнозируемых по экономике на год, в котором наступила смерть этого лица.

Следует подчеркнуть, что в соответствии с п.11 Положения о назначении и выплате пособия в случае смерти одного из супругов, утвержденного Постановлением Правительства № 712/2019 [6] (далее - Положение) величина ПВ, которая выплачивалась на день смерти ее получателя, подтверждается на основании информации, содержащейся в Информационной системе «Социальная помощь» Национальной кассы социального страхования (НКСС).

Далее, исходя из содержания Постановления Правительства № 923/2020 [7], размер среднемесячной заработной платы по экономике, прогнозируемой на 2021 год, составляет сумму 8716 MDL.

Следовательно, если смерть супруга наступила в 2021 году (после вступления в силу Закона № 156/2019), то пережившему супругу предоставляется ЕПСС, размер которого не может превышать потолок в пяти среднемесячных заработных плат, прогнозируемых по экономике на упомянутый год, который составляет, таким образом, максимальную сумму величиной 43.680 (8716 х 5) MDL(очевидно, что оснований для не превышения такого внушительного потолка в 2021 году будут возникать редко на практике).

При этом, необходимо отметить, что согласно п.14 Положения назначенное ЕПСС не пересматривается и не индексируется (в дальнейшем), в том числе в случае прогнозирования Правительством в будущие года более высокого размера среднемесячной заработной платы по экономике, к примеру, на следующий 2022 год и далее.

3. Из существа ч. (3) комментируемой ст.1 Закона № 156/2019 и п.12 Положения вытекает, что ЕПСС выплачивается пережившему супругу ежемесячно в течение периода, рассчитываемого по следующей правовой формуле:

$$
\mathbf{T}=5-\mathrm{p}, \quad \text { где: }
$$

$\mathbf{T}$ - период, в течение которого переживший супруг вправе получать ЕПСС (продолжительность которого не может превышать пяти лет);

p - период, за который умерший супруг получил ПВ (например, 4 года).

Иначе говоря, ЕПСС выплачивается пережившему супругу ежемесячно в течение периода равного промежутку/интервалу, на протяжении которого умерший супруг получал ПВ (например, в рамках трех или четырех лет), но длительность которого, при любом раскладе, не должна превышать максимум пятилетний срок.

Важно учесть, что в силу предписаний п.13 Положения в случае, когда пережившему супругу назначена ЕПСС, в период его выплаты (продолжительность которого не может превышать пяти лет), он не вправе одновременно потребовать назначение и выплату также пенсии по случаю потери кормильца (ППК) согласно ст.24 - 27 Закона о ГПС.

Однако, по истечении периода, в течение которого переживший супруг получал ЕПСС (к примеру, по истечении данного периода в 2024 году), он в дальнейшем будет вправе претендовать на получение, полагающейся ему на общих основаниях ППК с учетом требований ст.24 - 27 Закона о ГПС.

4. Нормой ч. (4) комментируемой ст.1 Закона № 156/2019 и предписаниями подп. b) п. 3 Положения установлено, что ЕПСС выплачивается/предоставляется пережившему супругу в случае, если на день насту- 
пления смерти получателя ПВ переживший супруг, независимо от возраста (до пенсионного или после пенсионного), состоял в браке с умершим супругом не менее 15 лет. При этом ЕПСС предоставляется независимо от того, является ли переживший супруг получателем той или иной пенсии в государственной пенсионной системе, но при одном важном условии: размер пенсии, выплачиваемой пережившему супругу, или реализованный им в месяц смерти супруга застрахованный месячный доход (заработная плата и др.) не должен превышать в 1,5 раза прожиточный минимум для пенсионеров согласно данным, имеющимся у Национального бюро статистики (НБС) на момент запроса пособия. Следует отметить, что прожиточный минимум для пенсионеров (и для других категорий граждан) определяется НБС с учетом требований Закона № 152/2012 о прожиточном минимуме [8] и Положения о порядке исчисления величины прожиточного минимума, утвержденного Постановлением Правительства № 902/2000 [9].

Иными словами, право на получение ЕПСС возникает только при условии, если на день наступления смерти получателя ПВ (к примеру, 25.05.2021 г.) переживший супруг, независимо от своего возраста, состоял юридически с умершим супругом в брачных отношениях не менее 15 лет (исходя из даты регистрации брака, указанной в свидетельстве о браке данных супругов и даты регистрации смерти супруга, указанной в свидетельстве об его смерти).

При этом, законодатель не обусловливает четко и однозначно, чтобы переживший супруг состоял только в одном браке с умершим супругом непрерывно в течение 15 и более лет подряд на день наступления смерти получателя ПВ (такое нахождение супругов в течение 15 и более лет в брачных отношениях логически/теоретически возможно/допустимо не только в одном единственном браке с умершим супругом, но суммарно и на основании двух или даже нескольких заключенных правомерно браков между ними же, если они, после прежнего развода/разводов между собой, не состояли в браке/браках с другими/третьими лицами).

Такой вывод (относительно нахождения супругов в течение 15 и более лет суммарно в брачных отношениях) вытекает, в свою очередь, из положений Гаагских конвенций по вопросам семьи и брака (1950-1980 гг.). А также, в частности, из смысла/логики ст.11 Конвенции о признании разводов и решений о раздельном жительстве супругов от 1 июня 1970 года [10] (к которой Молдова присоединилась на основании Закона №106/2011 [11]), согласно которой государство, обязанное признать развод (в РМ прекращение брака путем развода супругов признано согласно ст.33-39 Семейного кодекса PM [12]), не может препятствовать новому браку любого из супругов (не исключая заключение нового брака между бывшими супругами). Учитывая при этом, что в силу ч. (1) ст. 8 Конституции РМ [13], наша страна обязалась соблюдать международные договоры/конвенции, одной из сторон которых она является, строить свои отношения с другими государствами на общепризнанных принципах и нормах международного права.

Во избежание ненужных и противоречивых трактовок на практике по вопросу нахождения супругов в течение 15 и более лет в брачных отношениях, целесообразно все же осуществление официального толкования указанных правовых положений с учетом требований ст.71 и 72 Закона о нормативных актах №100/2017 [14].

Наряду с этим, законодатель определяет, что пережившему супругу - ЕПСС может быть назначена, независимо от факта получения им той или иной разновидности государственной пенсии (например: ПВ; пен- 
сии по ограничению возможностей; пенсии по случаю потери кормильца; специиальной пенсии; досрочной пенсии по возрасту; пенсии за выслугу лет и др.) или от факта неполучения оным какого-либо вида государственной пенсии (из-за отсутствия правовых оснований для ее назначения и др.).

В контексте разъясненных законодательных норм, п. 3 Положения уточняет дополнительно, что ЕПСС предоставляется пережившему супругу при выполнении следующзих условий:

$>\quad$ на дату смерти умерший супруг получал ПВ менее пяти лет после установления права на такую пенсию (к примеру, в течение трех лет после назначения ПВ);

$>$ переживший супруг, независимо от возраста, состоял в браке с умершим супругом не менее 15 лет (скажем, с 2003 по 2021 гг.);

$>$ ЕПСС было востребовано пережившим супругом в течение трех лет со дня смерти своего супруга (например, 10.05.2022 г. если супруг умер после 01.01.2020 г.).

5. Из смысла ч. (5) комментируемой ст.1 Закона № 156/2019 и предписаний подп. с) п. 3 Положения надлежит, что право на получение ЕПСС может быть востребовано пережившим супругом в течение трех лет со дня наступления смерти супруга.

Так, например, если муж получал ПВ в течение четырех лет после назначения ему указанной пенсии в 2017 году, и он умер в нынешнем году (к примеру, 30.04.2021 г.), то при таких обстоятельствах, его пережившая жена (вдова), независимо от наличия или отсутствия у нее статуса пенсионера, вправе будет претендовать на получение ЕПСС (путем письменного обращения в ТКСС в установленном порядке) в любое время в течение (не позднее) трех непрерывных лет, исчисляемых со дня наступления смерти своего мужа (30.04.2021г.), зафиксированного в свидетельстве об его смерти, и до исчисляемой даты истечения указанного трехлетнего периода.

При этом важно акцентировать, что упомянутый трехлетний период должен быть исчислен с учетом требований ст.387 Гражданского кодекса РМ [15] (ГК), согласно которым год считается равным тремстам шестидесяти пяти дням.

Статья 2. Обращение за назначением пособия

(1) Заявление о назначении пособия подается лично пережившим супругом в территориальный орган социального страхования по месту жительства с предъявлением документов, подтверждающих право на пособие.

(2) Порядок обращения за пособием устанавливается Правительством.

1. Нормой ч. (1) комментируемой ст.2 Закона № 156/2019 предусмотрено, что заявление о назначении ЕПСС подается лично пережившим супругом в ТКСС по месту жительства с предъявлением документов, подтверждающих право на такое пособие.

Исходя из положений ст.38 ГК, местом жительства физического лица (в том числе, пережившего супруга) признается место обычного пребывания. Лицо считается имеющим данное место жительства до тех пор, пока не приобрело другое. Место обычного пребывания основывается на тесной и стабильной связи физического лица с соответствующим местом. При определении места обычного пребывания учитываются все относящиеся к делу фактические элементы, в частности продолжительность и регулярность присутствия лица в соответствующем месте, а также условия и основания этого присутствия.

В свою очередь, ст.39 ГК определяет, что до тех пор, пока не будет доказано обратное, место жительства или место временного пребывания физического лица (пережившего супруга) предполагается в месте, указанном как таковое в удостоверении 
личности или, по обстоятельствам, в другом удостоверяющем личность документе, предусмотренном законом, а точнее - в том или ином конкретном документе, указанном в ст.1 Закона об удостоверяющих личность документах национальной паспортной системы № 273/1994 [16] (к которым относятся: все типы паспортов, удостоверений личности, виды на жительство и проездные документы лиц без гражданства, беженцев и бенефициариев гуманитарной защиты).

Таким образом, заявление о назначении ЕПСС (к которому должны быть приложены документы, подтверждающие право на такое пособие) подается лично пережившим супругом в ТКСС по своему месту жительства (например, в мун. Бэлць), определяемом с учетом положений ст.38 и 39 ГК (изложенных детально выше).

2. Как явствует из содержания ч. (2) комментируемой ст.2 Закона № 156/2019, конкретный порядок обращения за ЕПСС устанавливается Правительством.

К основному правительственному нормативному акту, регламентирующему конкретный порядок обращения за ЕПСС, относится в настоящее время упомянутое выше Положение. В частности, п.5 Положения предписывает, что заявление о назначении ЕПСС в случае смерти одного из супругов подается лично пережившим супругом, с предъявлением подтверждающих документов, в ТКСС по месту жительства пережившего супруга, и регистрируется в обязательном порядке. Заявление подается согласно образцу, установленному НКСС.

Статья 3. Назначение и выплата пособия

(1) Пособие назначается с месяца подачи заявления. В случае подачи заявления в месяц наступления смерти супруга пособие назначается со следующего месяца.

(2) Выплата пособия производится ежемесячно за текущий месяц поставщиком платежных услуг на территории Респу- блики Молдова, назначенным получателем пособия в порядке, установленном Правительством.

(3) В случае если переживший супруг обращается за назначением пособия, предусмотренного настоящим законом, в период его выплаты он не имеет права на назначение и выплату пенсии по случаю потери кормильца в соответствии с Законом о государственной пенсионной системе № 156/1998.

(4) В случае смерти получателя пособия невостребованная сумма другому лицу не выплачивается.

(5) Удержания из ежемесячного пособия производятся в соответствии с положениями статьи 38 Закона о государственной пенсионной системе № 156/1998.

1. Положениями ч. (1) комментируемой ст.3 Закона № 156/2019 уточняется, что ЕПСС назначается с месяца подачи заявления. В случае подачи заявления в месяц наступления смерти супруга пособие назначается со следующего месяца.

Иными словами, ЕПСС должно быть назначено ТКСС с месяца подачи заявления (точнее, с месяца регистрации в установленном порядке данного заявления в ТКСС), если оно было подано не в месяц наступления смерти супруга (к примеру, в феврале 2021 года), а позже (например, в марте - мае 2021 года).

В случае же когда заявление о назначении ЕПСС было подано (оперативно) в месяц наступления смерти супруга (скажем, в апреле 2021 года) - данное пособие будет назначено не с месяца подачи заявления (апрель 2021 года), а со следующего месяца (то есть, с мая 2021 года).

В контексте изложенного, п. 8 Положения предусматривает, что предоставление права на ЕПСС или отклонение заявления осуществляется на основании решения, вынесенного ТКСС и подписанного его руководителем, в 30-дневный срок со дня 
подачи заявления со всеми необходимыми документами (точнее, со дня регистрации данного заявления с приложенными правовыми актами в ТКСС).

Наряду с этим, п.9 Положения обозначает, что решение ТКСС об отклонении заявления о назначении ЕПСС, с указанием конкретных причин отказа, должно быть направлено заявителю в 5-дневный срок со дня его вынесения.

2. Из существа ч. (2) комментируемой ст.3 Закона № 156/2019 следует, что выплата ЕПСС производится ежемесячно за текущий месяц поставщиком платежных услуг на территории РМ, назначенным получателем этого пособия в порядке, установленном Правительством.

В этой связи, предписаниями п.17-19 Положения конкретизировано, что ЕПСС выплачивается посредством метода платежа, выбранного получателем и доступного в правительственной услуге электронных платежей (MРау). Суммы ЕПСС, установленные и не полученные получателем в течение 12 месяцев подряд, приостанавливаются. Выплата ЕПСС возобновляется на основе заявления получателя или представителя, уполномоченного доверенностью, и удостоверения личности заявителя, поданных в ТКСС, и выплачиваются в ретроактивном порядке с даты приостановления. Лица, преклонного возраста или по состоянию здоровья, которые не могут самостоятельно получать ЕПСС у поставщика платежных услуг, оно доставляется на дом на основании заявления, поданного и принятого поставщиком платежных услуг.

3. Нормой ч. (3) комментируемой ст.3 Закона № 156/2019 и предписанием п.13 Положения зафиксировано, что в случае, когда переживший супруг обращается за назначением ЕПСС, в период его выплаты он не имеет права на назначение и выплату пенсии по случаю потери кормильца (ППК) в соответствии с Законом о ГПС.
Следовательно, в случае, когда пережившему супругу назначена ЕПСС, в период его выплаты (продолжительность которого не может превышать пятилетний срок), он не имеет право на назначение и выплату параллельно ППК согласно ст.24 - 27 Закона о ГПС.

Однако, по истечении периода, в течение которого переживший супруг был вправе получать ЕПСС (к примеру, в 2024 году), он в дальнейшем будет вправе претендовать на получение, полагающейся ему на общих основаниях ППК с учетом требований ст.24 - 27 Закона о ГПС.

В частности, требованиями ст.24 Закона о ГПС установлено, что ППК назначается, если умерший был получателем ПВ. ППК назначается независимо от продолжительности страхового стажа в случае, если смерть кормильца наступила вследствие производственной травмы или профессионального заболевания.

4. Из предписаний ч. (4) комментируемой ст.3 Закона № 156/2019 и п.26 Положения вытекает, что в случае смерти получателя ЕПСС, невостребованная (оставшаяся неполученной) сумма другому лицу в дальнейшем не выплачивается.

В контексте отмеченных правовых предписаний, п.23 и 25 Положения уточняют дополнительно и шире, что выплата ЕПСС в случае смерти одного из супругов, назначенная, но не востребованная в течение 12 месяцев пережившим супругом, прекращается. Выплата ЕПСС возобновляется в ретроактивном порядке с месяца подачи получателем заявления и документов, удостоверяющих его личность, в ТКСС, с даты приостановления. ЕПСС, назначенное и не выплаченное своевременно пережившему супругу, не может быть выплачено другому лицу.

5.Правило, закрепленное в ч.(5) комментируемой ст.3 Закона № 156/2019 предусматривает, что удержания из ЕПСС производятся в соответствии с положениями ст. 38 Закона о ГПС. 
В частности, рассмотрение процитированного правила через призму требований ч.(1) ст. 38 Закона о ГПС и п.27 Положения позволяет констатировать, что удержания из ЕПСС в случае смерти одного из супругов производятся на основании:

$\checkmark$ исполнительных документов, согласно Исполнительному кодексу РМ [17] (ИК);

$\checkmark$ решений, вынесенных НКСС или ТКСС с целью взыскания не причитающихся получателю сумм, выплаченных ему в виде ЕПСС.

Наряду с этим, п.27 Положения определяет, что суммы в виде ЕПСС, выплаченные необоснованно по вине получателя, удерживаются ежемесячно в размере, не превышающем 20\% от размера ЕПСС, но на основе заявления получателя процент удержания может быть увеличен до 100\%. В случае смерти получателя, необоснованно выплаченные ЕПСС не взыскиваются.

\section{бий \\ Статья 4. Источник выплаты посо-}

Пособия, назначенные в соответствии с настоящим законом, выплачиваются из бюджета государственного социального страхования.

1. Комментируемые положения ст.4 Закона № 156/2019 предусматривают, что ЕПСС выплачивается из бюджета государственного социального страхования (БГСС).

В этой связи необходимо отметить, что согласно ч.(1) ст.131 Конституции РМ, БГСС является составной частью национального публичного бюджета (наряду с государственным бюджетом и бюджетов районов, городов и сел).

С другой стороны, нормами ч.(2) ст. 31 и ст.33 Закона о публичных финансах и бюджетно-налоговой ответственности № 181/2014 [18] предписано, что БГСС администрируется (управляется) НКСС. Отношения между государственным бюджетом и БГСС реализуются посредством:
- трансфертов специального назначения, предназначенных для предоставления социальных выплат (включая ЕПСС) и других расходов, которые по действующему законодательству несет государственный бюджет через БГСС (объем таких трансфертов устанавливается в соответствии с законодательством в области социальной защиты, включая Закон № 156/2019);

- трансфертов из государственного бюджета для покрытия недостаточности доходов БГСС в случае, когда ресурсы БГСС не покрывают его расходов.

2. Следует также отметить, что ст.4 3акона № 156/2019 находит свое определенное развитие в предписаниях п.31 и 32 Положения, согласно которым, НКСС ежемесячно перечисляет на текущий счет в качестве средств, временно находящихся в пользовании пенитенциарных учреждений, финансовые средства, предназначенные для выплаты пособий, а администрация пенитенциарного учреждения распределяет поступившие на данный счет суммы на лицевые счета осужденных. Пенитенциарные учреждения до 4 числа месяца, следующего за отчетным периодом, представляют НКСС отчеты о полученных и распределенных на лицевые счета осужденных сумMax.

Статья 5. Заключительные и переходные положения

(1) Положения настоящего закона применяются в случае наступления смерти после 1 января 2020 года.

(2) Правительству в трехмесячный срок со дня опубликования настоящего закона в Официальном мониторе Республики Молдова принять нормативные акты, необходимые для его исполнения.

1. Из содержания ч.(1) комментируемой ст.5 Закона № 156/2019 подобает, что правовые нормы названного закона могут быть юридически применены только к случаям наступления смерти после 01.01.2020 г. 
К случаям наступления смерти до 24 часов 31.12.2019 г. включительно - правовые нормы Закона № 156/2019 не применяются.

Необходимо отметить, что текст ч.(1) ст.5 Закона № 156/2019 исходит из требований ст. 76 Конституции страны, согласно которым закон вступает в силу в день его опубликования в Официальном мониторе РМ (ОМ РМ) или в срок, предусмотренный в самом законе, который в соответствии с п/п. b) п. 1 Постановления Конституционного суда № 32/1998 «О толковании ст. 76 Конституции Республики Молдова «Вступление закона в силу» [19] не может предшествовать дате официального опубликования.

В тоже время, рассматриваемая ч.(1) ст.5 Закона № 156/2019 согласуется в полной мере с положениями ч.(3) и (4) ст.73 Закона о нормативных актах №100/2017, предписывающих, что нормативный акт действует только в период обладания юридической силой и, как правило, не может иметь обратной силы. Обратную силу имеют только нормативные акты, смягчающие ответственность.

2. Исходя из предписаний ч.(2) комментируемой ст.5 Закона № 156/2019, Парламент поручил Правительству в трехмесячный срок со дня опубликования настоящего закона в ОМ РМ принять нормативные акты, необходимые для его исполнения.

Как известно, текст Закона № 156/2019 был опубликован полностью в ОМ РМ 13.12.2019 г. Следовательно, Правительство должно было в трехмесячный срок (13.12.2019 г. - 12.03.2020 г.) разработать, согласовать, принять и опубликовать в ОМ РМ нормативные акты, необходимые для правильного применения норм Закона № $156 / 2019$ и четкого их исполнения в полном объеме.

В этой связи, следует подчеркнуть, что основной нормативный акт (упомянутое выше Положение), предписания которого были использованы в полной мере в процессе аргументирования/изложения настоящих комментарий, был утвержден Правительством в срочном порядке и опубликован полностью в ОМ РМ от 31.12.2019 г., что позволило НКСС и ТКСС приступить к четкому и грамотному исполнению/применению норм Закона № 156/2019, начиная без задержек с 01.01.2020 г. и продолжать дальше.

Наряду с этим, не исключено, что для правильного применения отдельных/спорных норм Закона № 156/2019 потребуется дополнительно разработка с последующим принятием Правительством других нормативных актов в этих целях, как того предусматривает ч.(2) ст.5 Закона № 156/2019.

\section{Заключение}

Полагаем, что изложенные в настоящей статье комментарии к Закону № 156/2019 позволяют оказать в целом необходимую и востребованную помощь в системном усвоении основных теоретических и практических правовых аспектов национального законодательства о социальном страховании и социальном обеспечении, регулирующих условия и процедуру предоставления пособия в случае смерти одного из супругов.

Одновременно, данные комментарии призваны способствовать совершенствованию процесса непрерывного юридического образования взрослых в сфере социально -трудовых отношений, как составной части обучения в течение всей жизни, обеспечивающей непрерывный доступ граждан к правовой науке, юридической информации, правовой культуре в целях гибкого и грамотного приспособления к новым, динамично меняющимся социально-экономическим условиям и развития необходимых для профессиональной и социальной деятельности современной личности. 


\section{Библиография}

1. Закон о предоставлении пособия в случае смерти одного из супругов № 156/2019 - Официальный монитор Республики Молдова, 2019 г., № 367-377, ст. 242.

2. Закон о государственной пенсионной системе № 156/1998 - повторное опубликование: Официальный монитор Республики Молдова, 2004 г., № 42-44, ст. 247.

3. Закон о государственной системе социального страхования № 489/1999 - Официальный монитор Республики Молдова, 2000 г., № $1-4$, ст. 2.

4. Закон о государственных социальных пособиях некоторым категориям граждан № 499/1999 - повторное опубликование: Официальный монитор Республики Молдова, 2014 г., № 87-91, ст. 214 .

5. Закон о пенсионном обеспечении военнослужащих и лиц начальствующего и рядового состава органов внутренних дел и Генерального инспектората карабинеров № 1544/1993 - повторное опубликование: Официальный монитор Республики Молдова, 2010 г., № 247251, ст. 752.

6. Положение о назначении и выплате пособия в случае смерти одного из супругов, утвержденное Постановлением Правительства № 712/2019 - Официальный монитор Республики Молдова, 2019 г., № 400-406, ст. 1049.

7. ПостановлениеПравительства№923/2020 «Об утверждении размера среднемесячной заработной платы по экономике, прогнозируемой на 2021 год» - Официальный монитор Республики Молдова, 2020 г., № 359, ст.923.

8. Закон № 152/2012 о прожиточном минимуме - Официальный монитор Республики Молдова, 2012 г., № 165, ст. 555.

9. Положение о порядке исчисления величины прожиточного минимума, утвержденное Постановлением Правительства № 902/2000 -
Официальный монитор Республики Молдова, 2013 г., № 104-108, ст. 344.

10. Конвенция о признании разводов и решений о раздельном жительстве супругов от 1 июня 1970 года - https://docs.cntd.ru.

11. Закон № 106/2011 о присоединении Республики Молдова к Конвенции о признании разводов и решений о раздельном жительстве супругов - Официальный монитор Республики Молдова, 2011 г., № 103-106, ст. 268.

12. Семейный кодекс Республики Молдова № 1316/2000 - Официальный монитор Республики Молдова, 2001 г., № 47-48, ст. 210.

13. Конституция Республики Молдова - повторное опубликование: Официальный монитор Республики Молдова, 2016 г., № 78, ст. 140.

14. Закон о нормативных актах №100/2017 Официальный монитор Республики Молдова, 2018 г., № 7-17, ст. 34.

15.Гражданский кодекс Республики Молдова № 1107/2002 - повторное опубликование: Официальный монитор Республики Молдова, 2019 г., № 66-75, ст. 132.

16. Закон об удостоверяющих личность документах национальной паспортной системы № 273/1994 - Официальный монитор Республики Молдова, 1995 г., № 9, ст. 89.

17.Исполнительный кодекс Республики Молдова № 443/2004 - повторное опубликование: Официальный монитор Республики Молдова, 2010 г., № 214-220, ст. 704.

18.Закон о публичных финансах и бюджетно-налоговой ответственности № 181/2014 - Официальный монитор Республики Молдова, 2014 г., № 223-230, ст.519.

19. Постановление Конституционного суда РМ № 32/1998 «О толковании ст. 76 Конституции Республики Молдова «Вступление закона в силу» - Официальный монитор Республики Молдова, 1998 г., № 100, ст.42. 